\title{
Neural growth hormone: regional regulation by estradiol and/or sex chromosome complement in male and female mice
}

\author{
Kayla M Quinnies ${ }^{1,2}$, Paul J Bonthuis ${ }^{3}$, Erin P Harris ${ }^{1,2}$, Savera RJ Shetty ${ }^{1,2}$ and Emilie F Rissman ${ }^{4^{*}}$
}

\begin{abstract}
Background: Sex differences in pituitary growth hormone $(\mathrm{GH})$ are well documented and coordinate maturation and growth. GH and its receptor are also produced in the brain where they may impact cognitive function and synaptic plasticity, and estradiol produces $G$ sex differences in rat hippocampus. In mice, circulating estradiol increases Gh mRNA in female but not in male medial preoptic area (MPOA); therefore, additional factors regulate sexually dimorphic Gh expression in the brain. Thus, we hypothesized that sex chromosomes interact with estradiol to promote sex differences in $\mathrm{GH}$. Here, we assessed the contributions of both estradiol and sex chromosome complement on Gh mRNA levels in three large brain regions: the hippocampus, hypothalamus, and cerebellum.

Methods: We used the four core genotypes (FCG) mice, which uncouple effects of sex chromosomes and gonadal sex. The FCG model has a deletion of the sex-determining region on the Y chromosome (Sry) and transgenic insertion of Sry on an autosome. Adult FCG mice were gonadectomized and given either a blank Silastic implant or an implant containing $17 \beta$-estradiol. Significant differences in GH protein and mRNA were attributed to estradiol replacement, gonadal sex, sex chromosome complement, and their interactions, which were assessed by ANOVA and planned comparisons.
\end{abstract}

Results: Estradiol increased Gh mRNA in the cerebellum and hippocampus, regardless of sex chromosome complement or gonadal sex. In contrast, in the hypothalamus, females had higher Gh mRNA than males, and XY females had more Gh mRNA than XY males and XX females. This same pattern was observed for $G H$ protein. Because the differences in $G h$ mRNA in the hypothalamus did not replicate prior studies using other mouse models and tissue from mPOA or arcuate nucleus, we examined GH protein in the arcuate, a subdivision of the hypothalamus. Like the previous reports, and in contrast to the entire hypothalamus, a sex chromosome complement effect showed that XX mice had more $\mathrm{GH}$ than $\mathrm{XY}$ in the arcuate.

Conclusions: Sex chromosome complement regulates GH in some but not all brain areas, and within the hypothalamus, sex chromosomes have cell-specific actions on GH. Thus, sex chromosome complement and estradiol both contribute to $\mathrm{GH}$ sex differences in the brain.

Keywords: Growth hormone, Sex differences, Estradiol, Sex chromosomes, Hypothalamus, Cerebellum, Growth hormone-releasing hormone, Obesity

\footnotetext{
* Correspondence: efrissma@ncsu.edu

${ }^{4}$ Department of Biological Sciences, North Carolina State University, Raleigh, NC 27695, USA

Full list of author information is available at the end of the article
} 


\section{Background}

Growth hormone $(\mathrm{GH})$ is synthesized in the pituitary and the brain [1,2]. Notably, like other anterior pituitary hormones, the secretion of $\mathrm{GH}$ is pulsatile and controlled by metabolic and neuroendocrine mechanisms [3-5]. There are long-established and well-documented sex differences in the frequency and amplitude of these $\mathrm{GH}$ pulses beginning during the peripubertal period in many mammalian species, including humans [6]. GH is also produced in the brain, where its distribution is extensive. GH receptors are present throughout the brain, and animal and human studies have implicated central $\mathrm{GH}$ signaling in neural functions [7]. For example, GH levels influence or are correlated with cognitive performance [8] and enhance excitatory hippocampal synaptic transmission [9]. GH also has neuroprotective effects, protecting from age-related hippocampal deficits in plasticity and learning [10] and against cerebellar damage following ischemic injury [11]. Additionally, GH has been broadly implicated in aging and neurogenesis, as neural precursor cells in the subventricular zone proliferate in response to central GH infusion [12]. Feeding behavior has also been linked to GH [13], and GH expression, in the hypothalamus specifically, is associated with sexually dimorphic body weight differences [14].

Regulation of GH differs by brain region. For example, in the hippocampus, Gh mRNA levels are lower prior to puberty and increased in post pubertal rats [15]. Also, Gh mRNA and protein expression are noted in many brain regions and known to be sexually dimorphic (females have higher mRNA expression and protein levels than males) in the hippocampus, preoptic area of the hypothalamus (mPOA), and arcuate nucleus in mice [16]. While sex differences in GH levels and release have been documented, the mechanisms that regulate these sex differences are not well explored.

Estradiol modulates GH protein and Gh mRNA expression in the rat hippocampus. In females, GH protein levels in the hippocampus are highest during estrus, when estradiol levels are elevated. In addition, ovariectomized rats express low levels of Gh mRNA and protein which increase following estradiol treatment [15]. In mice, the arcuate nucleus and the mPOA express sexually dimorphic Gh mRNA with females having higher levels than males. After gonadectomy, Gh mRNA decreases in females but not in males. Interestingly, castration actually increases $G h$ expression in the mPOA. Neurons containing GH protein also contain estrogen receptor alpha, and the anti-estrogen tamoxifen blocks the effects of estradiol on GH in females [16]. Thus, estradiol may regulate $\mathrm{GH}$ in females but not in males. In addition, the numbers of $\mathrm{X}$ chromosomes have a direct effect on Gh mRNA in the mouse mPOA (animals with two $\mathrm{X}$ chromosomes have higher levels than those with one $\mathrm{X}$ ), and two genes on the $\mathrm{X}$ chromosome known to escape $\mathrm{X}$ inactivation are correlated with $G$ expression in this region [14].

Taken together, existing data suggest that both estradiol and sex chromosome complement have actions on Gh mRNA and protein in a region-specific manner in the brain. Given the broad implications and regional specificity of $\mathrm{GH}$, its regulation is important to assess. In this report, we tested these two factors simultaneously in three diverse brain regions: the hypothalamus, hippocampus, and cerebellum. We used the four core genotypes (FCG) mice, which have been previously utilized to compare sex chromosome versus gonadal sex as sources of sex differences $[17,18]$. In the FCG mice, gonadal sex is unlinked from the sex chromosomes by deletion of the sex-determining region on the $\mathrm{Y}$ chromosome (Sry) and transgenic insertion of Sry on an autosome [19]. The FCG cross produces four types of offspring: normal females with ovaries and XX chromosome genotype (XXF), females with ovaries and XY genotype (XYF), males with testes and XY genotype (XYM), and males with testes and XX genotype (XX males). To manipulate estradiol, adult gonadectomized mice were treated with chronic implants containing estradiol or no hormone. We report that estradiol treatment increased Gh mRNA significantly in the hippocampus and cerebellum. Sex chromosome complement was a factor only in the hypothalamus where XY females had the highest levels of GH protein and mRNA. Because the sex chromosome complement effect was in the opposite direction from our past reports in wild type and another sex chromosome mutant mouse model, we quantified $\mathrm{GH}$ protein in the arcuate nucleus. We replicated our previous finding that $\mathrm{XX}$ mice have more GH than $\mathrm{XY}$ mice in the arcuate, regardless of gonadal sex.

\section{Methods \\ Animals}

All procedures were approved by and conducted in accordance with the University of Virginia Animal Care and Use Committee guidelines. The mice used for all experiments were the FCG mice on a C57BL/6) background. The FCG mice are XX females, XY females, XX males, and XY males [18]. Mice were maintained on a 12:12 light cycle (lights on at 1:00 pm). Animals had access to water and food (\# 7912 from Harlan Teklad, Madison, WI) ad libitum.

\section{Gonadectomy and hormone replacement}

All mice between 75 and 85 days of age were gonadectomized. At the time of surgery, each mouse received a subcutaneous implant made of a 5-mm Silastic tube (Dow Corning, Corp., Midland, MI; $1.98 \mathrm{~mm}$ inner diameter $\times 3.18 \mathrm{~mm}$ outer diameter). Implants were 
either filled with $2 \mathrm{mg} / \mathrm{ml} 17 \beta$-estradiol benzoate in sesame oil $(25 \mu \mathrm{l})$ or empty. During the surgery, mice were anesthetized with isoflurane. Following surgery, mice were given $0.9 \%$ sodium chloride subcutaneously and $0.25 \%$ bupivacaine as an analgesic and individually housed. All eight groups contained at least seven animals at the time of surgery.

\section{Tissue collection}

Animals were anesthetized with isoflurane and killed by cervical dislocation 3 weeks after surgery. Brains were then collected and quickly free hand dissected on ice. The cerebellum was gently separated from the inferior colliculi and brainstem, and the hypothalamus was removed from the ventral surface of the brain by gently separating it from the cerebral hemispheres, brainstem, and the optic chiasm. The hippocampus was carefully separated from the cortex, hindbrain, and diencephalon by removing the cerebral cortex with an incision at the end of the hemisphere and one $2 \mathrm{~mm}$ rostral to the first incision. Next, the cortex was removed, which revealed the hippocampus. All tissue was rapidly frozen following dissection to preserve for RNA extraction. Estradiolimplanted animals that were designated for Western blots had the whole brain removed and rapidly frozen on dry ice.

\section{Quantitative real-time PCR}

RNA was isolated from the brain tissue (Qiagen RNeasy Kit), and cDNA was generated from RNA by reverse transcription with Applied Biosciences High Capacity cDNA Reverse Transcription Kit. Real-time PCR was performed using the Applied Biosystems StepOne Plus for SYBR Green-based detection with Fast SYBR ${ }^{\circ}$ Green Master Mix. Biological replicate samples of $5 \mathrm{ng}$ were run in triplicate, and the average was used for data analysis. Quantification of Gh (F: 5'-AGGCCCAGCAGAG AACCGACA, R: 5'-ACGGTCCGAGGTGCCGAACA; source sequences: AK019954, AK030419, AL604045, BB024006, Consensus CDS: CCDS25554.1, UniProtKB/ Swiss-Prot: P06880) gene expression levels was calculated based on the threshold cycle for each well using the provided software and normalized to B2M (F: 5'-GGCTCAC ACTGAATTCACCCCCAC, R: 5' -ACATGTCTCGATCC CAGTAGACGGT; source sequence: AK019389, Consensus CDS: CCDS16654.1, UniProtKB/Swiss-Prot: P01887) for hippocampus and cerebellum endogenous controls; the endogenous control for hypothalamic tissue was Ppib (F: 5'-TGGAGAGCACCAAGACAGACA, R: 5'-TGCC GGAGTCGACAATGAT; source sequences: AK002357, AL363449, CA321924, Consensus CDS: CCDS23301.1, UniProtKB/Swiss-Prot: P24369, UniProtKB/TrEMBL: Q9DCY1). Melting curves revealed that only one factor per primer was amplified and that there were no measurable primer-dimers. A no-template control was also run to verify that amplification only occurred in the presence of cDNA. Both B2M [20-22] and Ppib $[14,23,24]$ have been used as controls in qRTPCR in our previous studies, and both B2M $[25,26]$ and Ppib $[27,28]$ have been shown to be stable controls in other work. Furthermore, there is no statistically significant difference between groups in this study in any of the tested brain regions in terms of the amplification time of either endogenous control gene (data not shown). No sex differences have been reported for these genes, and we did not find any significant difference in the amplification time for either control gene (data not shown). The total number of individual cerebellum processed was 50 (blank: XYM $N=7, \mathrm{XXM} N=7$, XXF $N=6, \mathrm{XYF} N=7$; E2: $\mathrm{XYM} N=6, \mathrm{XXM} N=8, \mathrm{XXF} N=4$, $\mathrm{XYF} N=5$ ). The total number of individual hippocampus processed was 53 (blank: XYM $N=6, \mathrm{XXM} N=7, \mathrm{XXF}$ $N=6, \mathrm{XYF} N=5, \mathrm{E} 2: \mathrm{XYM} N=9, \mathrm{XXM} N=8, \mathrm{XXF} N=6$, $\mathrm{XYF} N=6$ ). The total number used for the hypothalamus was 48 (6 per group).

\section{Western blotting}

Fresh frozen brains from estradiol-treated animals were cut into $120-\mu \mathrm{M}$ coronal sections in a cryostat and frozen on glass microscope slides, and protein was extracted from either punch of the arcuate nucleus or microdissected hypothalamus samples as described previously [16]. For protein extraction, tissue was thawed and homogenized in $10 \mathrm{mM}$ Tris, $400 \mathrm{mM} \mathrm{Nacl}, 1 \mathrm{mM}$ DTT, $1 \mathrm{mM}$ EDTA, and 10\% glycerol, with $10 \mu \mathrm{l} / \mathrm{ml}$ protease inhibitor cocktail (Sigma) and phenylmethylsulfonyl fluoride $(1 \mathrm{mM})$. After centrifugation, the total lysate protein concentrations were determined by BCA protein assay (Pierce Chemical Co., Cat\# 23228.). Proteins were separated on $14 \%$ polyacrylamide-SDS gels and transferred to nitrocellulose membranes. After transfer, membranes were blocked with $5 \%$ milk and incubated with an antibody for GH (1:5,000; National Hormone \& Peptide Program, CA) overnight at $4^{\circ} \mathrm{C}$. After rinsing, blots were incubated for $1 \mathrm{~h}$ with HRP-conjugated anti-rabbit IgG secondary antibody (1:10,000; Vector Laboratories) followed by detection on X-ray film (X-OMAT) with SuperSignal West Pico Chemiluminescent Substrate (Pierce Chemical Co.). The same blots were re-probed with the monoclonal antibody against $\beta$-actin at 1:10,000 (Sigma-Aldrich Corp.). The intensities of GH and $\beta$ actin bands on individual films were measured and analyzed by densitometry with ImageJ program (NIH). Levels of GH protein were normalized to those of $\beta$ actin in each sample, and the protein amount was expressed as the ratio of $\mathrm{GH}$ to $\beta$-actin. For the hypothalamus, 13 individual samples only from the estradioltreated groups were used (XYM $N=4, \mathrm{XXM} N=3, \mathrm{XXF}$ 
$N=3$, XYF $N=3$ ). For the analysis of the arcuate nucleus, six animals from each genotype, all estradiol treated, were assessed.

\section{Statistical analysis}

All data were analyzed using NCSS (2001). For gene expression data, normalized gene expression was calculated using the $\Delta \Delta C_{\mathrm{t}}$ method [29]. Relative quantities (RQs) were log transformed and analyzed by ANOVA with sex chromosome complement, gonadal sex, and hormone treatment as factors. For protein data, two-way ANOVAs were used with genotype and gonadal sex as the two factors. Significant results were assessed by Fisher's exact post hoc tests that adjust significance levels to take multiple comparisons into account.

\section{Results}

Estradiol increases Gh mRNA in the hippocampus and cerebellum

Estradiol significantly increased $G$ hene expression in both the hippocampus and cerebellum. FCG mice that were treated with an estradiol implant at the time of gonadectomy had higher levels of mRNA in the cerebellum than those that were given a blank implant (Figure $1 \mathrm{~A} ; F_{1,49}=8.61, P<0.006$ ), demonstrating for the first time that estradiol increases $G h$ mRNA levels in the cerebellum. Confirming previous results in rats [15], estradiol-treated FCG mice had higher levels of mRNA in the hippocampus than gonadectomized mice without any hormone replacement (Figure $1 \mathrm{~B} ; F_{1,52}=$ $5.78, P<0.03)$. There were no main effects of gonadal sex and sex chromosome complement, nor were there any significant interactions.

In the hypothalamus, gonadal sex and sex chromosome complement modify Gh mRNA

In the hypothalamus of FCG mice, there was a main effect of gonadal sex; males had less $G$ h expression as compared to females (Figure $1 C ; F_{1,47}=4.41, P<0.05$ ). An interaction between gonadal sex and sex chromosome complement $\left(F_{1,47}=9.21, P<0.01\right)$ was produced because XY female mice had higher $G h$ mRNA than XY male mice $(P<0.05)$. Animals given estradiol implants at the time of gonadectomy tended to have higher levels of

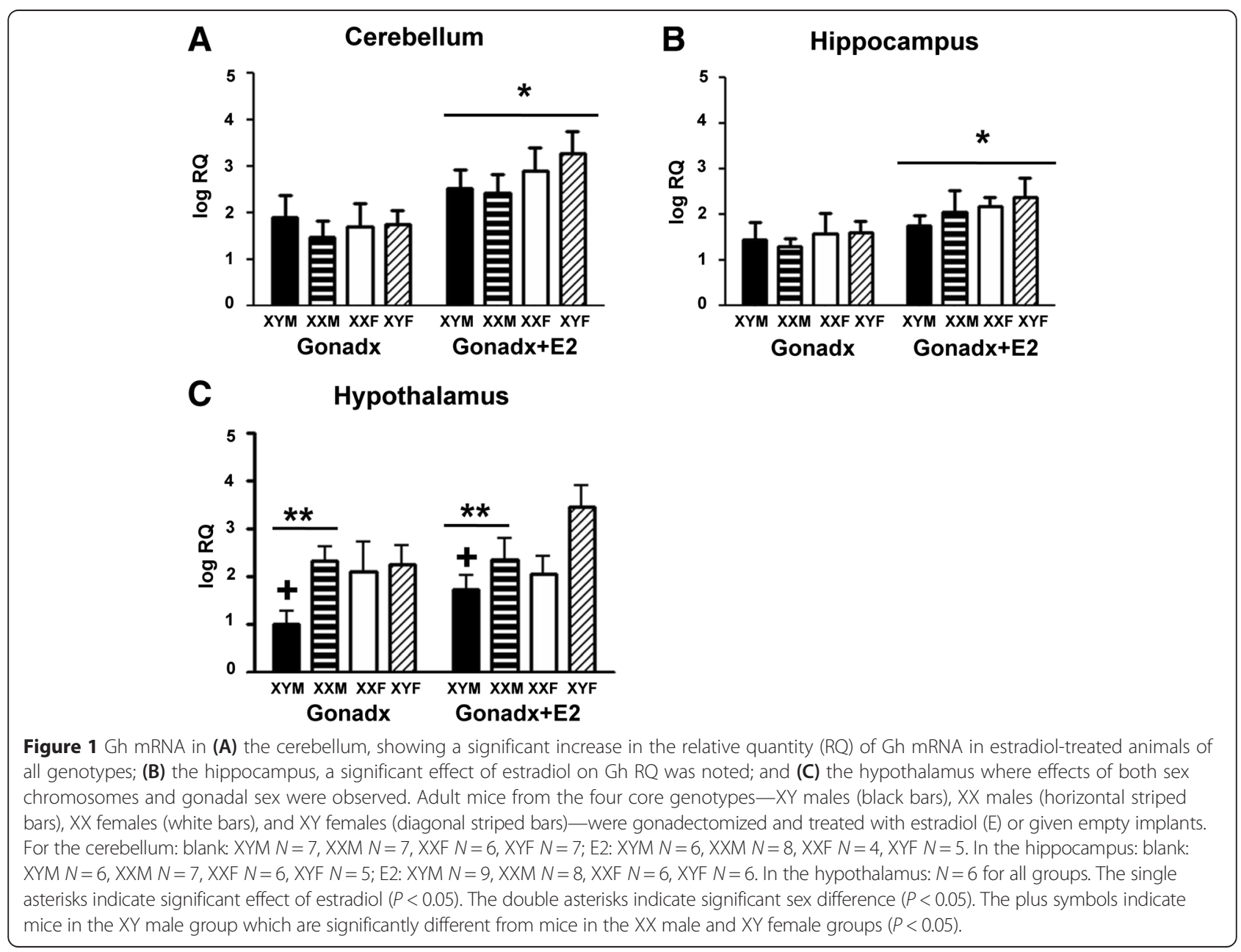


mRNA than those that were given a blank implant at the time of gonadectomy, but this effect was not significant $\left(F_{1,47}=2.69, P=0.11\right)$.

Sex chromosome complement modifies GH protein in the whole hypothalamus of estradiol-treated animals In the hypothalamus, we noted an interaction between gonadal sex and sex chromosomes. Female mice had higher Gh protein than males, and XY animals had more Gh than $\mathrm{XX}$ mice $\left(F_{1,13}=20.04, P<0.002\right)$. The amount of $\mathrm{GH}$ in $\mathrm{XY}$ female hypothalamus tissue was significantly greater than that in all other groups $(P<0.05)$. There was also a main effect of gonadal sex wherein females had more GH protein than males (Figure 2; $F_{1,13}=9.75, P<0.02$ ) and a main effect of sex chromosome complement $\left(F_{1,13}=7.59\right.$, $P<0.03)$ where $\mathrm{GH}$ levels in $\mathrm{XY}$ animals were greater than in $\mathrm{XX}$ animals.

Sex chromosome complement modifies GH protein in the arcuate nucleus of the hypothalamus

In the arcuate nucleus of the hypothalamus, we also noted an effect of sex chromosomes in estradiol-treated gonadectomized FCG mice (Figure $3 ; F_{1,20}=5.45, P<0.04$ ). In this nucleus, $\mathrm{XX}$ mice had higher levels of $\mathrm{GH}$ protein than $\mathrm{XY}$ mice, regardless of gonadal sex $(P<0.05)$. No gonadal sex effect or interactions were present.

\section{Discussion}

Our data show that estradiol treatment increases $G h$ gene expression in the cerebellum and hippocampus with a marginal effect in the hypothalamus, and that sex chromosome complement is correlated with Gh mRNA in the hypothalamus. Sex chromosome complement affects GH protein in the whole hypothalamus as well as the arcuate nucleus. Previous studies conducted by our lab showed that Gh mRNA is elevated in response to estradiol in the normal C57BL/6 female mouse hypothalamus, but not in males [16]. In combination with the current finding that $\mathrm{GH}$ protein is dependent on sex chromosomes in the whole hypothalamus as well as the arcuate nucleus, we suggest that estradiol and sex chromosome genes both regulate hypothalamic Gh gene expression.

Evidence for direct action of estradiol on $\mathrm{GH}$, and factors that mediate GH release, has existed for many years. In rats, neurons containing GH-releasing factor (GHRF) in the hypothalamus and $\mathrm{GH}$ cells in the pituitary coexpress estrogen receptors [30]. In mice, agonist binding to estrogen receptors alpha and beta induces expression of $G h$ in the pituitary [31]. Moreover, estradiol increases Gh mRNA in the mPOA and arcuate nucleus of female mice, and the estrogen receptor antagonist tamoxifen blocks this effect [16]. Estradiol treatment also stimulates $\mathrm{GH}$ secretion in humans, increasing the amount of $\mathrm{GH}$ per pulse twofold $[4,5]$. In addition, $\mathrm{GH}$ receptor

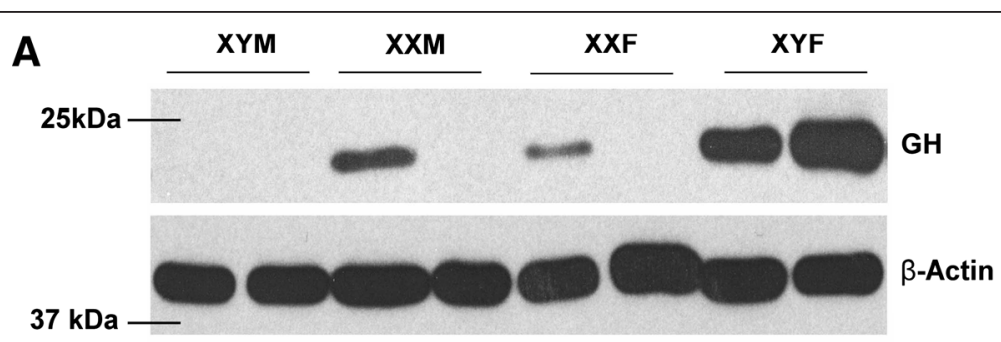

B

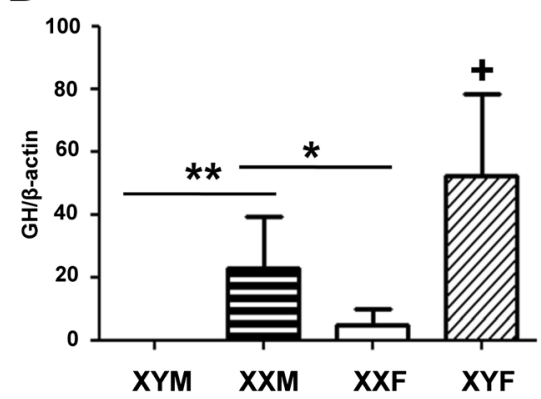

Figure $\mathbf{2} \mathrm{GH}$ protein in the hypothalamus. (A) A representative blot is shown. (B) Densitometry data from the blots is presented. Adult mice from the four core genotypes_-XY males (XYM N=4, black bars), XX males (XXM N=3, horizontal striped bars), XX females (XXF $N=3$, white bars), and $X Y$ females (XYF $N=3$, diagonal striped bars) — were gonadectomized and treated with estradiol (E). The single asterisk denotes significant effect of sex chromosome complement $(P<0.05)$. The double asterisks denote significant effect of gonadal sex $(P<0.05)$. The plus symbol denotes $X Y$ females which are significantly different from all other groups $(P<0.05)$. 

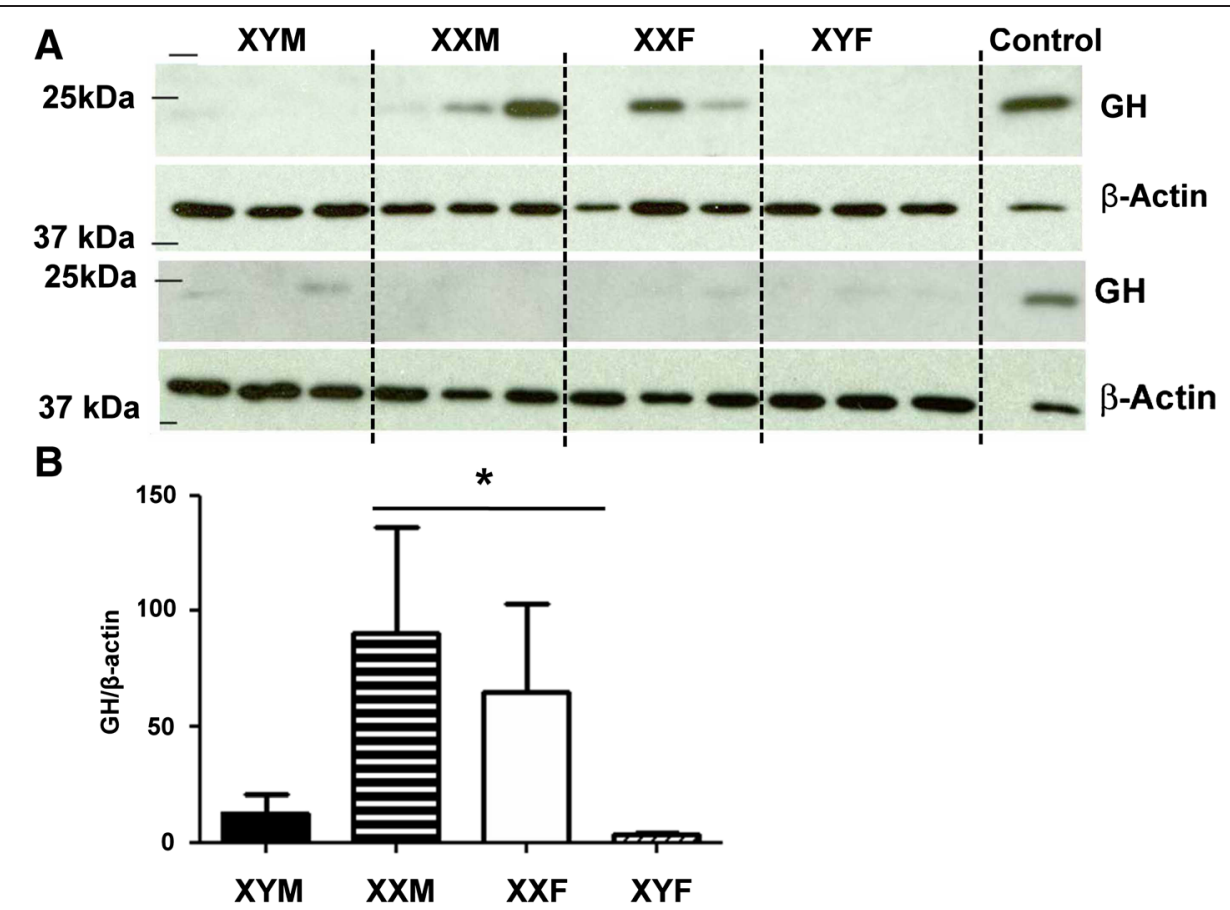

Figure $\mathbf{3} \mathrm{GH}$ protein in the arcuate nucleus of the hypothalamus. (A) A representative blot is shown. (B) Densitometry data from the blots is presented. Adult mice from the four core genotypes-XY males (black bars), XX males (horizontal striped bars), XX females (white bars), and XY females (diagonal striped bars)—were gonadectomized and treated with estradiol (E). $N=6$ in each group. The single asterisk signifies significant effect of sex chromosome complement $(P<0.05)$.

expression and $\mathrm{GH}$ binding increase in an estradioldependent manner in rat and human bone cell lines [32], and this relationship between estradiol and GH extends to the liver [33] and ovaries [34]. It is clear from these previous findings, and more so now with the addition of this study, that estradiol has an important regulatory effect on Gh mRNA and GH protein. While a relationship in the hypothalamus and rat hippocampus was known, we now show that this is true in multiple brain regions, which we expect to have widespread implications.

Given the presence of sex differences in Gh expression across several brain areas, we speculate that GH may regulate sexually dimorphic processes throughout the body. For example, Gh gene expression in the brain correlates with increased food consumption and body weight in mice $[13,14]$ and has been implicated in feeding behavior and energy homeostasis $[35,14]$. In a previous study using FCG mice, XY mice, independent of gonadal sex, were more sensitive to the reward of palatable food intake [36], which may be representative of the differences that we saw in GH. This would likely be due to actions in the hypothalamus, particularly in the arcuate nucleus, which has a known role in metabolism and feeding behavior. In addition, GH deficiency has been linked with cognitive impairment [16,35,37], and previous research has shown that Gh expression increases in the rat hippocampus following repeated learning in response to eye-blink conditioning [38]. In mice, infusion of GH into the hippocampus changes expression of immediate early genes and induces spontaneous locomotion, grooming, and anxiety-like behavior [39]. Consistent with observations in rat, our data in mice show that $G$ is expressed in the hippocampus in a hormone-dependent manner; this may be an important aspect of learning and memory mediation by $G h$. The cerebellum is also notably important for motor function and learning [40], and we show that estradiol regulates $G h$ levels in this region too.

Pituitary GH release is sexually dimorphic [41], and estradiol is an important activating factor in this sex difference [42]. When thinking in terms of sexual dimorphism, it is imperative to consider that estradiol and other hormones are often the only contributing element. However, steroid hormones also commonly function in conjunction with, and in addition to, sex chromosome complement, which is further reinforced by the data in this study. Sex chromosome complement is an important factor for sex differences and is implicated in sexually dimorphic outcomes of aggression [43], social interaction [43-45], and body weight [46-48]. Our data show the significance of sex chromosome complement for Gh gene expression and GH protein in the hypothalamus and the arcuate nucleus of the hypothalamus. The use of the FCG mice in these experiments demonstrates 
that the sex differences in these regions are not caused exclusively by estradiol, instead suggesting that these two principal mechanisms (estradiol and sex chromosomes) are acting together. We have observed a similar interaction in previous work. An interaction between $E R \alpha$ and sex chromosomes regulates calbindin gene expression in the prefrontal cortex and cerebellum of mice [49]. Notably, Gh and calbindin are autosomal genes, and the mechanism driving sex chromosome complement influence on autosomal gene expression is unclear. One strong possibility is that genes on the $\mathrm{X}$ chromosome that escape $\mathrm{X}$ inactivation modulate autosomal gene expression. Consistent with this proposition, Gh expression in the POA positively correlates with the combined levels of two X chromosome genes: $K d m 5 c$ and $K d m 6 a$, which encode lysine demethylases [14]. KDM5c (lysine demethylase 5c) specifically demethylates Histone 3 Lysine 4 (H3K4) marks, acting as a transcriptional repressor. KDM6a demethylates Histone 3 Lysine 27 (H3K27) and is a transcriptional activator of gene transcription. Both $K d m 5 c$ and $K d m 6 a$ escape $\mathrm{X}$ inactivation dosage compensation and therefore have higher expression levels in $\mathrm{XX}$ females (as well as FCG XX males) $[50,51]$. These $\mathrm{X}$ chromosome genes may modulate estradiol and sex chromosome actions in the hypothalamus.

An intriguing aspect of these data is the substantial variance in the levels of Gh mRNA and GH protein within individuals in the genotypes that have the highest amounts of GH. This same variability was noted in our first two studies in normal C57BL/6 mice and in the aneuploid $Y^{*}$ mutant line [16,14]. Secretion of GH from the pituitary is pulsatile throughout the day [3-5]; therefore, we speculate that GH may be likewise produced and released via an ultradian rhythm. Moreover, this hypothesis suggests that GH produced in the hypothalamus is involved in the regulation of pituitary GH. If such a role for neural GH exists, gene and protein expression of GH in neural cells could respond to feedback from peripheral GH concentrations commensurate with secretory pulsatility. The pulsatility in $\mathrm{GH}$ secretion from the pituitary is sexually dimorphic, and X chromosome dosage may play a role in the dimorphism [41] in addition to regulation by hormones. The mice in our study were gonadectomized and received an estradiol or blank implant. Thus, endogenous fluctuations of circulating estradiol do not account for the individual variation we have noted both in GH protein and mRNA.

These data indicate that mRNA levels measured in the whole hypothalamus are comparable to whole hypothalamic protein levels. However, the direction of the relationship between amounts of GH and the sex chromosomes, with XYF hypothalami containing the greatest amounts of $\mathrm{GH}$ and message, is in stark contrast to the data we collected in the arcuate and mPOA in normal C57BL/6 mice [8]. In that study, females (XX) had more Gh mRNA than males $(\mathrm{XY})$. In the aneuploidy (XY* model) mouse mutant, we measured Gh mRNA in mPOA and found a significant positive relationship between levels of $G h$ and numbers of $\mathrm{X}$ chromosomes [9]. Thus, our protein data from the arcuate nucleus in the FCG mice is in agreement with the data collected in normal mice. The fact that the entire hypothalamus and the arcuate are regulated differently by sex chromosome complement suggests cellular differences in the transcriptional regulation of GH. Cellular phenotypes in the hypothalamus are not uniform, and one hypothesis is that estrogen receptor alpha, which is co-expressed in nearly all GH-positive neurons in the arcuate nucleus and mPOA [16], interacts with sex chromosome genes that escape $\mathrm{X}$ inactivation.

\section{Conclusions}

We have shown that Gh gene expression is influenced by estradiol in the cerebellum and hippocampus. In the hypothalamus, an interaction between estradiol and sex chromosome complement was produced by the differences in $\mathrm{XY}$ male and female mice, with males having the lowest GH protein and mRNA and females having the greatest amounts. In estradiol-treated mice, GH protein levels in the arcuate nucleus were dependent on sex chromosome complement since XX mice of both gonadal sexes had higher levels than XY mice. This work draws attention to sex differences of $G$ gene expression and $\mathrm{GH}$ protein in previously unexplored areas of the brain. Future research should focus more on regionspecific roles for Gh in physiological processes and behavior, as well as which $\mathrm{X}$ chromosome genes have a role in autosomal gene expression and how they act in conjunction with steroid hormones.

\section{Competing interests}

The authors declare that they have no competing interests.

\section{Authors' contributions}

KMQ performed surgery on the mice, removed and dissected all tissue for the mRNA studies, and carried out the molecular protocols with the cerebellar tissue. PJB carried out mRNA protocols with the whole hypothalamic tissue. EPH carried out mRNA protocols with the hippocampal tissue and did the whole hypothalamus Western blots. SRJS punched arcuate nucleus from whole brain tissue and performed arcuate nucleus Western blots. EFR conceived the study and participated in its design and coordination and helped to draft the manuscript. All authors participated in statistical analysis and read and approved the final manuscript.

\section{Acknowledgements}

This work was funded by NIH grant R01 MH057759. PJB was supported on T32 GM08715. We thank Ms. Aileen Ryalls for excellent animal care.

\section{Author details}

'Department of Biochemistry and Molecular Genetics, University of Virginia School of Medicine, Charlottesville, VA 22908, USA. ${ }^{2}$ Neuroscience Graduate Program, University of Virginia School of Medicine, Charlottesville, VA 22908, USA. ${ }^{3}$ Department of Neurobiology and Anatomy, University of Utah, 20 
North 1900 East, Salt Lake City, UT 84132-3401, USA. ${ }^{4}$ Department of Biological Sciences, North Carolina State University, Raleigh, NC 27695, USA.

Received: 10 January 2015 Accepted: 13 March 2015 Published online: 28 April 2015

\section{References}

1. Kopchick JJ, Andry JM. Growth hormone $(\mathrm{GH}), \mathrm{GH}$ receptor, and signal transduction. Mol Genet Metab. 2000;71(1-2):293-314. doi:10.1006/ mgme.2000.3068.

2. Harvey S. Extrapituitary growth hormone. Endocrine. 2010;38(3):335-59. doi:10.1007/s12020-010-9403-8.

3. Painson JC, Tannenbaum GS. Sexual dimorphism of somatostatin and growth hormone-releasing factor signaling in the control of pulsatile growth hormone secretion in the rat. Endocrinology. 1991;128(6):2858-66. doi:10.1210/endo-128-6-2858

4. Shah N, Evans WS, Veldhuis JD. Actions of estrogen on pulsatile, nyctohemeral, and entropic modes of growth hormone secretion. Am J Physiol. 1999;276(5 Pt 2):R1351-8.

5. Veldhuis JD, Anderson SM, Kok P, Iranmanesh A, Frystyk J, Orskov H, et al. Estradiol supplementation modulates growth hormone $(G H)$ secretory-burst waveform and recombinant human insulin-like growth factor-l-enforced suppression of endogenously driven $\mathrm{GH}$ release in postmenopausal women. J Clin Endocrinol Metab. 2004;89(3):1312-8. doi:10.1210/jc.2003-031482.

6. Muller EE. Neural control of somatotropic function. Physiol Rev. 1987;67(3):962-1053.

7. Harvey S, Hull K. Neural growth hormone: an update. J Mol Neurosci. 2003:20(1):1-14. doi:10.1385/JMN:20:1:1.

8. Falleti MG, Maruff P, Burman P, Harris A. The effects of growth hormone $(\mathrm{GH})$ deficiency and $\mathrm{GH}$ replacement on cognitive performance in adults: a meta-analysis of the current literature. Psychoneuroendocrinology. 2006;31(6):681-91. doi:10.1016/j.psyneuen.2006.01.005.

9. Mahmoud GS, Grover LM. Growth hormone enhances excitatory synaptic transmission in area CA1 of rat hippocampus. J Neurophysiol. 2006;95(5):2962-74. doi:10.1152/jn.00947.2005.

10. Ramsey MM, Weiner $J L$, Moore TP, Carter CS, Sonntag WE. Growth hormone treatment attenuates age-related changes in hippocampal short-term plasticity and spatial learning. Neuroscience. 2004;129(1):119-27. doi:10.1016/j.neuroscience.2004.08.001.

11. Alba-Betancourt C, Luna-Acosta JL, Ramirez-Martinez CE, Avila-Gonzalez D, Granados-Avalos $E_{1}$ Carranza M, et al. Neuro-protective effects of growth hormone $(\mathrm{GH})$ after hypoxia-ischemia injury in embryonic chicken cerebellum. Gen Comp Endocrinol. 2013;183:17-31. doi:10.1016/j.ygcen.2012.12.004.

12. Blackmore DG, Reynolds BA, Golmohammadi MG, Large B, Aguilar RM, Haro L, et al. Growth hormone responsive neural precursor cells reside within the adult mammalian brain. Sci Rep. 2012;2:250. doi:10.1038/srep00250.

13. Bohlooly YM, Olsson B, Bruder CE, Linden D, Sjogren $K$, Bjursell M, et al. Growth hormone overexpression in the central nervous system results in hyperphagia-induced obesity associated with insulin resistance and dyslipidemia. Diabetes. 2005;54(1):51-62.

14. Bonthuis PJ, Rissman EF. Neural growth hormone implicated in body weight sex differences. Endocrinology. 2013. doi: 10.1210/en.2013-1234.

15. Donahue CP, Kosik KS, Shors TJ. Growth hormone is produced within the hippocampus where it responds to age, sex, and stress. Proc Natl Acad Sci U S A. 2006;103(15):6031-6. doi:10.1073/pnas.0507776103.

16. Addison ML, Rissman EF. Sexual dimorphism of growth hormone in the hypothalamus: regulation by estradiol. Endocrinology. 2012;153(4):1898-907. doi:10.1210/en.2011-1982

17. Arnold AP, Chen X. What does the "four core genotypes" mouse model tell us about sex differences in the brain and other tissues? Front Neuroendocrinol. 2009;30(1):1-9. doi:10.1016/j.yfrne.2008.11.001.

18. De Vries GJ, Rissman EF, Simerly RB, Yang LY, Scordalakes EM, Auger CJ, et al. A model system for study of sex chromosome effects on sexually dimorphic neural and behavioral traits. J Neurosci. 2002;22(20):9005-14.

19. Cox KH, Bonthuis PJ, Rissman EF. Mouse model systems to study sex chromosome genes and behavior: relevance to humans. Front Neuroendocrinol. 2014;35(4):405-19. doi:10.1016/j.yfrne.2013.12.004.

20. Cox KH, So NL, Rissman EF. Foster dams rear fighters: strain-specific effects of within-strain fostering on aggressive behavior in male mice. PLoS One. 2013;8(9), e75037. doi:10.1371/journal.pone.0075037.
21. Abel $J$ L, Rissman EF. Running-induced epigenetic and gene expression changes in the adolescent brain. Int J Dev Neurosci. 2013;31(6):382-90. doi:10.1016/j.ijdevneu.2012.11.002.

22. Stolzenberg DS, Stevens JS, Rissman EF. Histone deacetylase inhibition induces long-lasting changes in maternal behavior and gene expression in female mice. Endocrinology. 2014;155(9):3674-83. doi:10.1210/en.2013-1946.

23. Wolstenholme JT, Edwards M, Shetty SR, Gatewood JD, Taylor JA, Rissman $\mathrm{EF}$, et al. Gestational exposure to bisphenol a produces transgenerational changes in behaviors and gene expression. Endocrinology. 2012;153(8):3828-38. doi:10.1210/en.2012-1195.

24. Wolstenholme JT, Rissman EF, Bekiranov S. Sexual differentiation in the developing mouse brain: contributions of sex chromosome genes. Genes Brain Behav. 2013;12(2):166-80. doi:10.1111/gbb.12010.

25. Stephens AS, Stephens SR, Morrison NA. Internal control genes for quantitative RT-PCR expression analysis in mouse osteoblasts, osteoclasts and macrophages. BMC Res Notes. 2011;4:410. doi:10.1186/1756-0500-4-410.

26. Thal SC, Wyschkon S, Pieter D, Engelhard K, Werner C. Selection of endogenous control genes for normalization of gene expression analysis after experimental brain trauma in mice. J Neurotrauma. 2008;25(7):785-94. doi:10.1089/neu.2007.0497.

27. Cao XM, Luo XG, Liang JH, Zhang C, Meng XP, Guo DW. Critical selection of internal control genes for quantitative real-time RT-PCR studies in lipopolysaccharide-stimulated human THP-1 and K562 cells. Biochem Biophys Res Commun. 2012;427(2):366-72. doi:10.1016/j.bbrc.2012.09.066.

28. Pachot A, Blond JL, Mougin B, Miossec P. Peptidylpropyl isomerase B (PPIB): a suitable reference gene for mRNA quantification in peripheral whole blood. J Biotechnol. 2004;114(1-2):121-4. doi:10.1016/j.jbiotec.2004.07.001.

29. Livak KJ, Schmittgen TD. Analysis of relative gene expression data using real-time quantitative PCR and the 2(-delta delta C(T)) method. Methods. 2001;25(4):402-8. doi:10.1006/meth.2001.1262.

30. Shirasu K, Stumpf WE, Sar M. Evidence for direct action of estradiol on growth hormone-releasing factor (GRF) in rat hypothalamus: localization of [3H] estradiol in GRF neurons. Endocrinology. 1990;127(1):344-9.

31. Avtanski D, Novaira HJ, Wu S, Romero CJ, Kineman R, Luque RM, et al. Both estrogen receptor alpha and beta stimulate pituitary GH gene expression. Mol Endocrinol. 2014;28(1):40-52. doi:10.1210/me.2013-1245.

32. Slootweg MC, Swolin D, Netelenbos JC, Isaksson OG, Ohlsson C. Estrogen enhances growth hormone receptor expression and growth hormone action in rat osteosarcoma cells and human osteoblast-like cells. J Endocrinol. 1997;155(1):159-64.

33. Fernandez-Perez L, Santana-Farre R, de Mirecki-Garrido M, Garcia I, Guerra B, Mateo-Diaz C, et al. Lipid profiling and transcriptomic analysis reveals a functional interplay between estradiol and growth hormone in liver. PLoS One. 2014;9(5):e96305. doi:10.1371/journal.pone.0096305.

34. Hrabia A, Sechman A, Rzasa J. Independent, non-IGF-I mediated, GH action on estradiol secretion by prehierarchical ovarian follicles in chicken. In vitro study. Folia Biol. 2012;60(3-4):213-7.

35. Sartorio A, Conti A, Molinari E, Riva G, Morabito F, Faglia G. Growth, growth hormone and cognitive functions. Horm Res. 1996;45(1-2):23-9.

36. Seu E, Groman SM, Arnold AP, Jentsch JD. Sex chromosome complement influences operant responding for a palatable food in mice. Genes Brain Behav. 2014;13(6):527-34. doi:10.1111/gbb.12143.

37. Chen X, McClusky R, Chen J, Beaven SW, Tontonoz P, Arnold AP, et al. The number of $X$ chromosomes causes sex differences in adiposity in mice. PLoS Genet. 2012;8(5), e1002709. doi:10.1371/journal.pgen.1002709.

38. Donahue CP, Jensen RV, Ochiishi T, Eisenstein I, Zhao M, Shors T, et al. Transcriptional profiling reveals regulated genes in the hippocampus during memory formation. Hippocampus. 2002;12(6):821-33. doi:10.1002/hipo.10058.

39. Srimontri $P$, Hirota H, Kanno H, Okada T, Hirabayashi $Y$, Kato K. Infusion of growth hormone into the hippocampus induces molecular and behavioral responses in mice. Exp Brain Res. 2014;232(9):2957-66. doi:10.1007/s00221-014-3977-y.

40. Gruart A, Yeo CH. Cerebellar cortex and eyeblink conditioning: bilateral regulation of conditioned responses. Exp Brain Res. 1995;104(3):431-48.

41. Jansson JO, Eden S, Isaksson O. Sexual dimorphism in the control of growth hormone secretion. Endocr Rev. 1985;6(2):128-50. doi:10.1210/edrv-6-2-128.

42. Birzniece V, Sutanto S, Ho KK. Gender difference in the neuroendocrine regulation of growth hormone axis by selective estrogen receptor modulators. J Clin Endocrinol Metab. 2012;97(4):E521-7. doi:10.1210/jc.2011-3347.

43. Gatewood JD, Wills A, Shetty S, Xu J, Arnold AP, Burgoyne PS, et al. Sex chromosome complement and gonadal sex influence aggressive and 
parental behaviors in mice. J Neurosci. 2006;26(8):2335-42. doi:10.1523/JNEUROSCI. 3743-05.2006.

44. McPhie-Lalmansingh AA, Tejada LD, Weaver JL, Rissman EF. Sex chromosome complement affects social interactions in mice. Horm Behav. 2008:54(4):565-70. doi:10.1016/j.yhbeh.2008.05.016.

45. Cox KH, Rissman EF. Sex differences in juvenile mouse social behavior are influenced by sex chromosomes and social context. Genes Brain Behav. 2011;10(4):465-72. doi:10.1111/j.1601-183X.2011.00688.x.

46. Arnold AP. Mouse models for evaluating sex chromosome effects that cause sex differences in non-gonadal tissues. J Neuroendocrinol. 2009;21(4):377-86. doi:10.1111/j.1365-2826.2009.01831.x.

47. Chen X, McClusky R, Itoh Y, Reue K, Arnold AP. X and Y chromosome complement influence adiposity and metabolism in mice. Endocrinology. 2013;154(3):1092-104. doi:10.1210/en.2012-2098.

48. Arnold AP, Chen $X$, Itoh $Y$. What a difference an $X$ or $Y$ makes: sex chromosomes, gene dose, and epigenetics in sexual differentiation. Handb Exp Pharmacol. 2012;214:67-88. doi:10.1007/978-3-642-30726-3_4.

49. Abel JM, Witt DM, Rissman EF. Sex differences in the cerebellum and frontal cortex: roles of estrogen receptor alpha and sex chromosome genes. Neuroendocrinology. 2011;93(4):230-40. doi:10.1159/000324402.

50. Greenfield A, Carrel L, Pennisi D, Philippe C, Quaderi N, Siggers P, et al. The UTX gene escapes $X$ inactivation in mice and humans. Hum Mol Genet. 1998;7(4):737-42.

51. Disteche CM, Filippova GN, Tsuchiya KD. Escape from X inactivation. Cytogenet Genome Res. 2002;99(1-4):36-43.

\section{Submit your next manuscript to BioMed Central and take full advantage of:}

- Convenient online submission

- Thorough peer review

- No space constraints or color figure charges

- Immediate publication on acceptance

- Inclusion in PubMed, CAS, Scopus and Google Scholar

- Research which is freely available for redistribution 